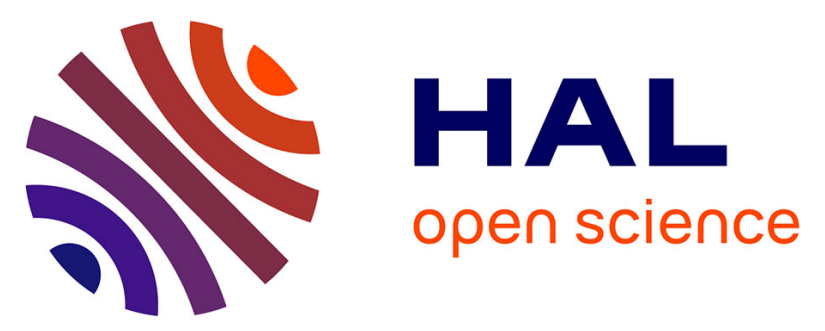

\title{
Synthesis, characterization and optical properties of new tetrafluorenyl-porphyrins peripherally functionalized with conjugated 2-fluorenone groups
}

Xu Zhang, Zhipeng Sun, Nicolas Richy, Olivier Mongin, Frédéric Paul, Mireille Blanchard-desce, Christine O. Paul-Roth

\section{To cite this version:}

Xu Zhang, Zhipeng Sun, Nicolas Richy, Olivier Mongin, Frédéric Paul, et al.. Synthesis, characterization and optical properties of new tetrafluorenyl-porphyrins peripherally functionalized with conjugated 2-fluorenone groups. New Journal of Chemistry, 2021, 45 (33), pp.15053-15062. 10.1039/d1nj01410b . hal-03245201

\author{
HAL Id: hal-03245201 \\ https://hal.science/hal-03245201
}

Submitted on 18 Oct 2021

HAL is a multi-disciplinary open access archive for the deposit and dissemination of scientific research documents, whether they are published or not. The documents may come from teaching and research institutions in France or abroad, or from public or private research centers.
L'archive ouverte pluridisciplinaire HAL, est destinée au dépôt et à la diffusion de documents scientifiques de niveau recherche, publiés ou non, émanant des établissements d'enseignement et de recherche français ou étrangers, des laboratoires publics ou privés. 


\title{
Synthesis, Characterization and Optical Properties of New Tetrafluorenyl-Porphyrins Peripherally functionalized with Conjugated 2-Fluorenone Groups
}

Xu Zhang, ${ }^{a}$ Zhipeng Sun, ${ }^{a}$ Nicolas Richy, ${ }^{a}$ Olivier Mongin, ${ }^{a}$ Frédéric Paul, ${ }^{*}$, a Mireille Blanchard-Desce, ${ }^{*, b}$ Christine O. Paul-Roth, ${ }^{*}, a$

Dedicated to a long-time experienced collaborator in the field of conjugated materials, Prof. Todd $B$. Marder, on the occasion of his $66^{\text {th }}$ birthday.

\footnotetext{
a Univ Rennes, INSA Rennes, CNRS, ISCR (Institut des Sciences Chimiques de Rennes) - UMR 6226, F-35000 Rennes, France

b Université de Bordeaux, Institut des Sciences Moléculaires (CNRS UMR 5255), 33405 Talence, France

*Corresponding authors: christine.paul@insa-rennes.fr and Frederic.paul@univ-rennes1.fr and mireille.blanchard-desce@u-bordeaux.fr
}

tel : (+33) (0) 223236372 fax: (+33) (0) 223236372

Electronic Supplementary Information (ESI) available: [details of any supplementary information available should be included here]. See DOI: 10.1039/x0xx00000x

\begin{abstract}
The synthesis of new meso-tetrafluorenylporphyrins peripherally functionalized with various 2-ethynyl fluorenyl and/or 2-ethynyl fluorenonyl arms is presented. The impact of these fluorenone units on their linear and nonlinear optical properties is also investigated. Thus, two-photon absorption and singlet oxygen photosensitising properties are evaluated. Relatively large
\end{abstract}

Keywords

Porphyrin * Fluorenone * Fluorescence * Oxygen Photosensitization * Two-Photon Absorption

Introduction 
Porphyrin are attractive because their properties can be fine-tuned by synthetic modifications of the peripheral substituents. ${ }^{[1-3]}$ In particular, we focus hereafter on a set of three new starshaped porphyrins decorated with extra peripheral fluorenone substituents.
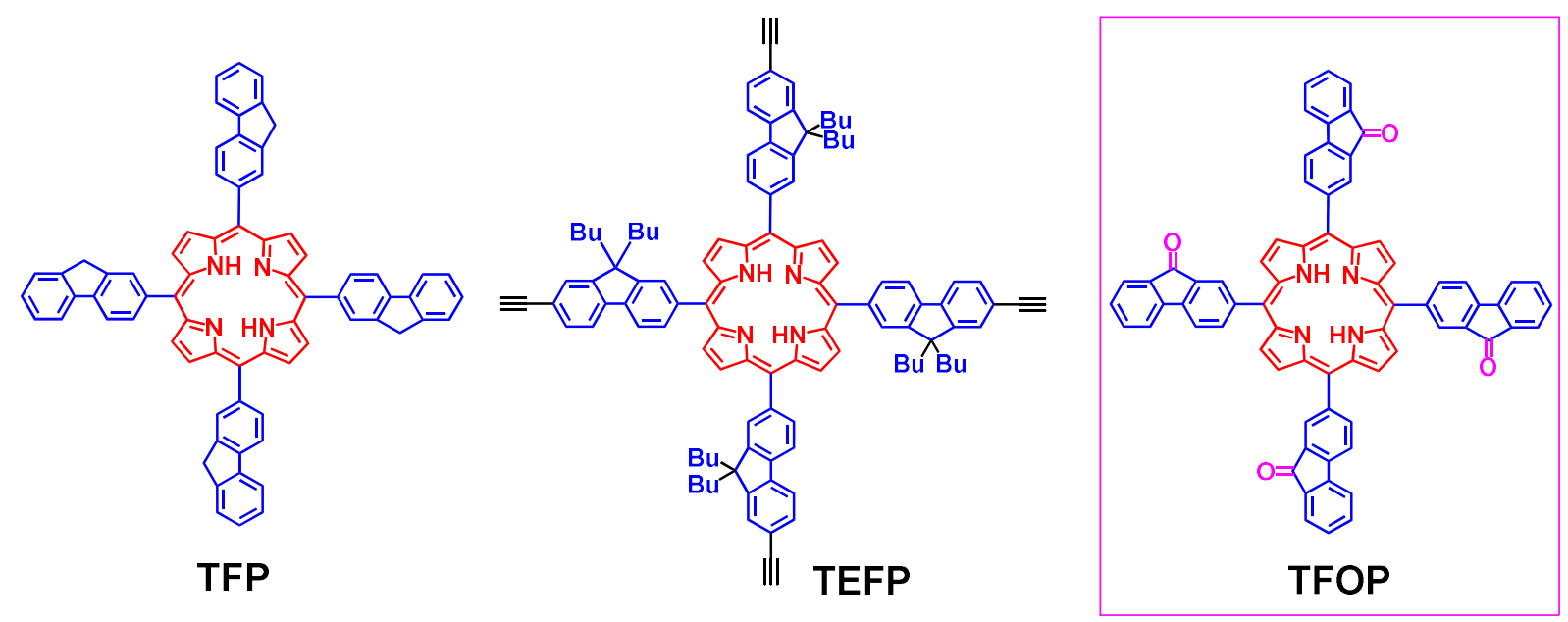

Scheme 1. Molecular structures of meso-tetrafluorenylporphyrin (TFP), the corresponding alkynyl-substituted compound tetra(7-ethynyl-2-fluorenyl)porphyrin (TEFP) and tetrafluorenonylporphyrin (TFOP).

Accordingly, in line with independent findings of Bo and coworkers, ${ }^{[4]}$ some of us had identified 5,10,15,20-tetrafluorenylporphyrin (TFP) as an appealing luminophore (Scheme 1). ${ }^{[5]}$ As a meso-tetraarylporphyrin, this compound presents a remarkable quantum yield (24\%) which can be ascribed to the 2-fluorenyl units. The same year we also found that a slightly higher quantum yield $\left(\Phi_{\mathrm{F}}=26 \%\right)$ could be obtained with the 2-fluorenone analogue (TFOP $)^{[6]}$ and later on that introduction of four 2-fluorenyl units at the periphery of a mesotetraphenylporphyrin core allows increasing further the light harvesting properties and luminescence quantum yield, provided that the fluorenyl units are conjugated with the central porphyrin. ${ }^{[7]}$ For instance, whereas TPP has an emission quantum yield around 11\%, TPP1 exhibits an improved emission quantum yield of $20 \%$. This yield can however not be further improved by attaching additional fluorenyl units at the periphery since neither TPP2 (20\%) nor TPP3 (19\%) present improved fluorescence quantum yields (Scheme 2). ${ }^{[7]}$ A similar statement was also made for the dendrimer series based on a meso-tetrafluorenylporphyrin core (TFP1-3 in scheme 3; see $\Phi_{\mathrm{F}}$ values). ${ }^{[8]}$ In contrast, when TFP-Bu was functionalized with pendant ethynyl groups at its periphery, as in TEFP (Scheme 1), the fluorescence quantum yield dropped to $15 \%$. This observation points to the strong influence of apparently slight structural modifications at the periphery of the TFP core on its emission properties. ${ }^{[8 b]}$ 


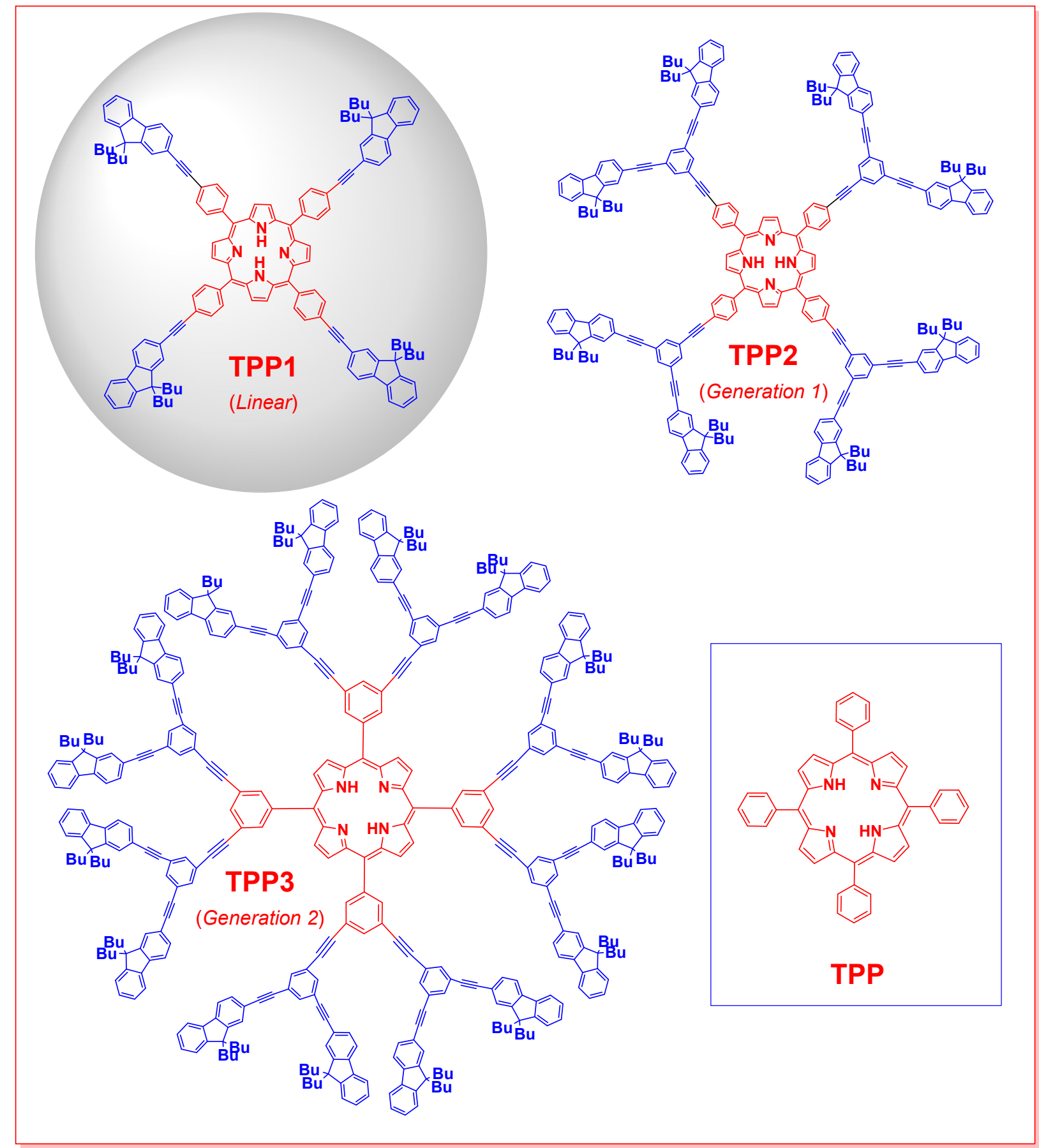

Scheme 2. Molecular structures of TPP-cored porphyrin dendrimers TPP1-TPP3 and their reference TPP. 


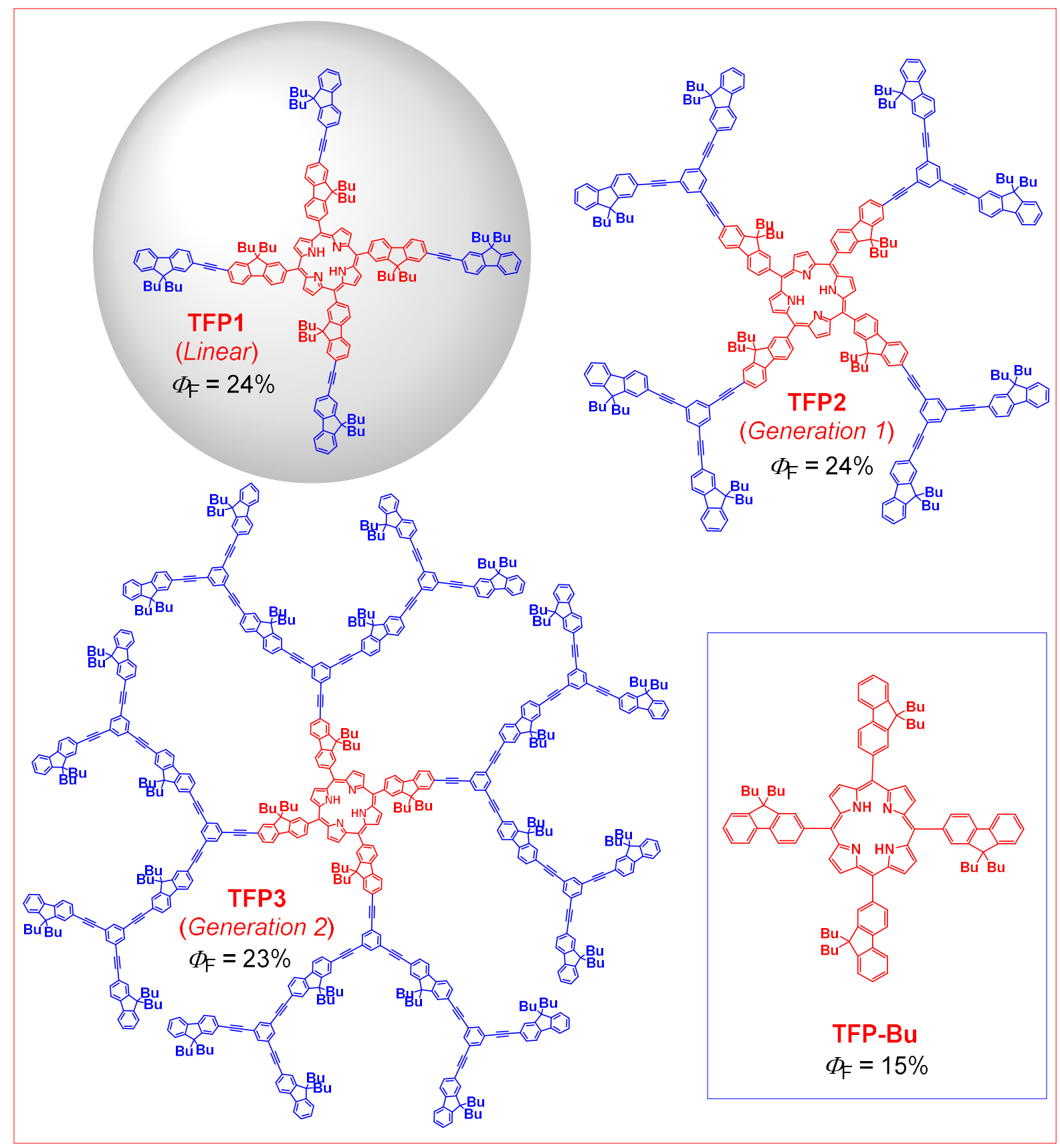

Scheme 3. Molecular structures of TFP-cored porphyrin dendrimers TFP1-TFP3 and reference TFP-Bu.

Important two-photon absorption (2PA) cross-sections were also evidenced for all these new dendritic systems in addition to their well-known oxygen-photosensitizing capability of the tetrapyrrolic core. ${ }^{[9]}$ Thus, besides applications related to OLEDs or color displays, ${ }^{[5 \mathrm{~b}-\mathrm{c}]}$ we also realized that, after proper functionalization, molecular analogues of TFP, series TPP1-3 or TFP1-3 might give rise to efficient biphotonic photosensitizers for photodynamic therapy (PDT).$^{[9,10]}$ Due to the practical advantages of two-photon excitation, this field is rapidly 
expanding and many porphyrin-based two-photon photosensitizers have been reported to date. ${ }^{[10,11]}$ Such innovative developments rest on the rapid intersystem crossing taking place between the singlet and triplet excited manifolds in porphyrins (which is the first reason for their limited luminescence) and the large 2PA cross-section that related dendrimeric systems can present. ${ }^{[7,8,12]}$ In our case, the intrinsic luminescence would even allow to perform simultaneous imaging, allowing an entry into so-called "two-photon theranostics". ${ }^{[10 b]}$ For these applications, in addition to the optimization of their luminescence quantum yields, simultaneous optimization of their two-photon cross-section and oxygen photosensitization quantum yields are also required. In this respect, systematic structure-property studies need to be conducted on new systems. Previous such studies pointed to star-shaped structures, such as TFP1, for possessing the most promising potential. ${ }^{[8 \mathrm{a}, 11 \mathrm{a}]}$ Accordingly, we have now decided to explore the impact of the replacement of the four terminal $9 H$-fluoren-2-yl (2-fluorenyl) groups by $9 H$-fluoren-9-one-2-yl (2-fluorenonyl) ones on the optical properties of interest (Scheme 4).
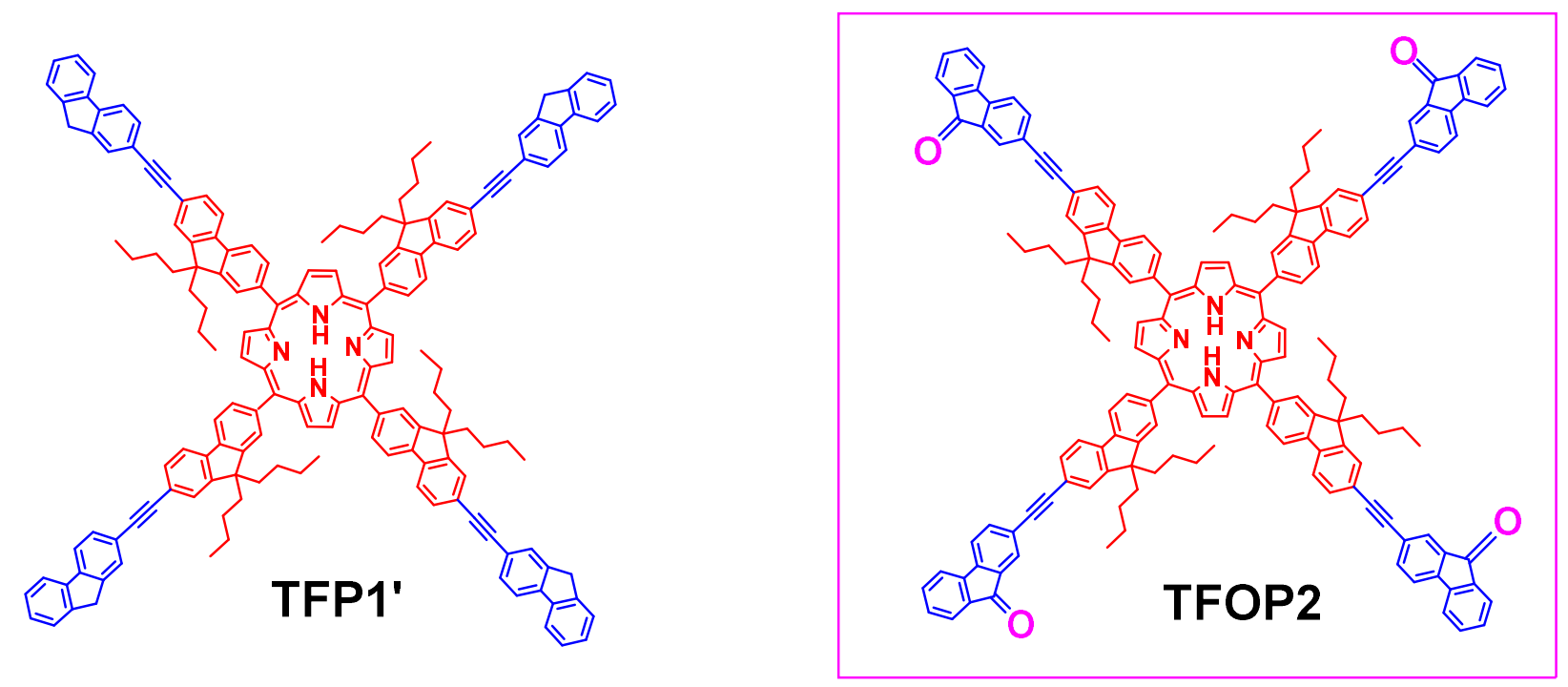

Scheme 4. Molecular structures of the targeted molecule TFOP2 vs. the reference compound TFP1'.

Accordingly, (i) the synthesis and characterization of two new star-shaped derivatives, TFOP2', a deoxidized analogue of TFOP2, and TFOP2, and of their precursor TFP1' will be described first. (ii) Their electronic absorption (1PA) and emission spectra, their oxygen photosensitization properties and their 2PA spectra will next be determined. (iii) Finally, the 
impact of peripheral 9-fluorenyl oxidation on the photophysical properties of TFP1' as well as the potential interest of TFOP2' and TFOP2 for PDT will be briefly discussed.

\section{Results and discussion}

\section{Porphyrin synthesis}

To synthesize the new star-shaped porphyrin TFOP2 featuring four fluorenone units at its periphery, a synthetic protocol adapted from that previously used to isolate $\mathbf{T F O P}^{[6]}$ was envisioned. Oxidation of TFP1' was expected to keep internal 2,7-fluorenyl units untouched and to form 2-fluorenone units specifically on external positions. During the course of this synthesis, one di-oxidized porphyrin isomer was isolated as a side-product "en route" toward TFOP2 and also characterized. Facile synthetic access to the required precursor TFP1' was expected using the Lindsey method, ${ }^{[13]}$ meaning that the corresponding linear difluorenyl aldehyde had to be synthesized first. This last compound (3) was obtained with fair yield $(63 \%)$ from a Sonogashira coupling reaction ${ }^{[14]}$ between the known aldehyde $\mathbf{1}^{[8 \mathrm{a}]}$ and 2ethynylfluorenyl $\mathbf{2}^{[7 \mathrm{a}]}$ (Scheme 5).

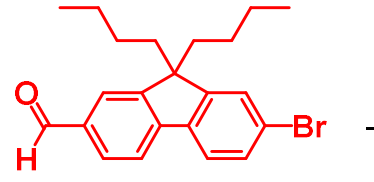

1

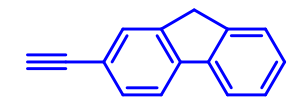

2

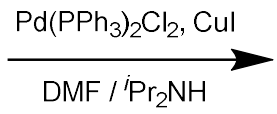

$(63 \%)$

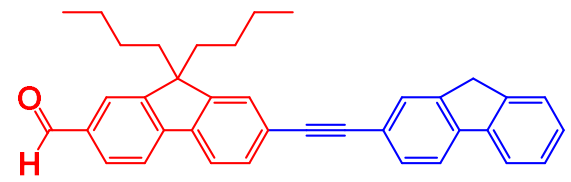

3

Scheme 5. Synthesis of the new linear difluorenyl aldehyde 3.

From this new aldehyde 3, the new TFP1' porphyrin was obtained using classic Lindsey conditions (Scheme 6). ${ }^{[13]}$ and isolated in correct yield (18\%), as a dark red powder after chromatographic separation. 


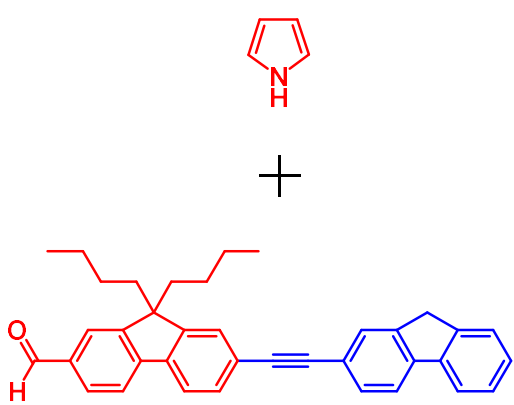

(1) $\mathrm{BF}_{3} \cdot \mathrm{OEt}_{2}, \mathrm{CHCl}_{3}$

(2) $p$-chloranil / $\mathrm{NEt}_{3}$

$(18 \%)$

\section{3}

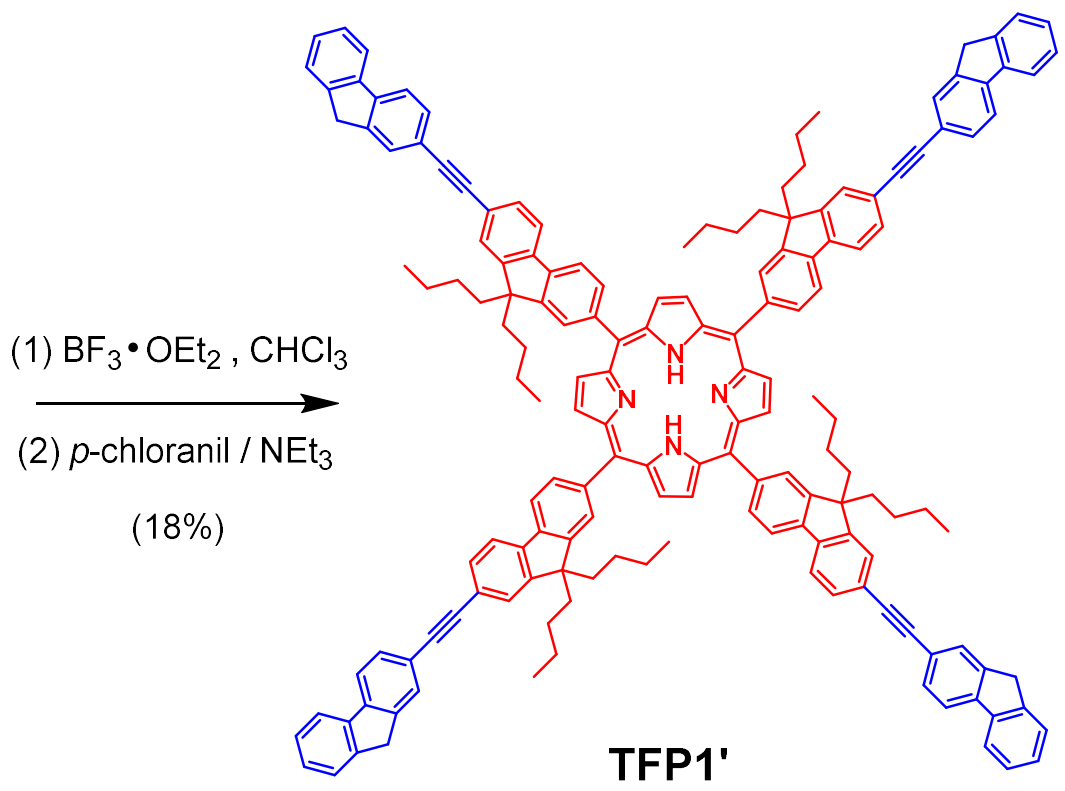

Scheme 6. Synthesis of non-oxidized porphyrin TFP1' under Lindsey conditions.

Likewise to the synthesis of TFOP previously obtained by oxidation of $\mathbf{T F P}^{[6]}$, the desired porphyrins were obtained from TFP1' (Scheme 7) by aerobic oxidation in a basic biphasic (organic/aqueous) medium using Aliquat 336 as the phase transfer agent. Each time, the disappearance of the starting compound TFP1' was monitored by TLC to ensure completion of the reaction. The partially oxidized symmetric porphyrin TFOP2' was isolated in 37\% as a dark red powder after chromatographic purification of the crude reaction mixture. These compounds were obtained after running the reaction in pure DMF for $59 \mathrm{~h}$, while the symmetrical A4 porphyrin TFOP2 was obtained similarly in 38\%, after running the reaction in a DMF/THF (1:1) mixture for $72 \mathrm{~h}$. During the formation of TFOP2', we noticed that the reaction medium contained many insolubles at the start of the reaction, whereas it is totally homogeneous in the DMF/THF solvent mixture. We believe that the formation of partially oxidized intermediates is favored when the synthesis of TFOP2 is attempted in DMF, because this solvent does not dissolve all the precursor TFP1' at the start of the reaction and thus will contribute to slow down the overall oxidation reaction. As a result, only TFOP2' could be separated by chromatography from the reaction mixture after $59 \mathrm{~h}$ in DMF, while other partially oxidized intermediates that must also have been formed were not isolated. 


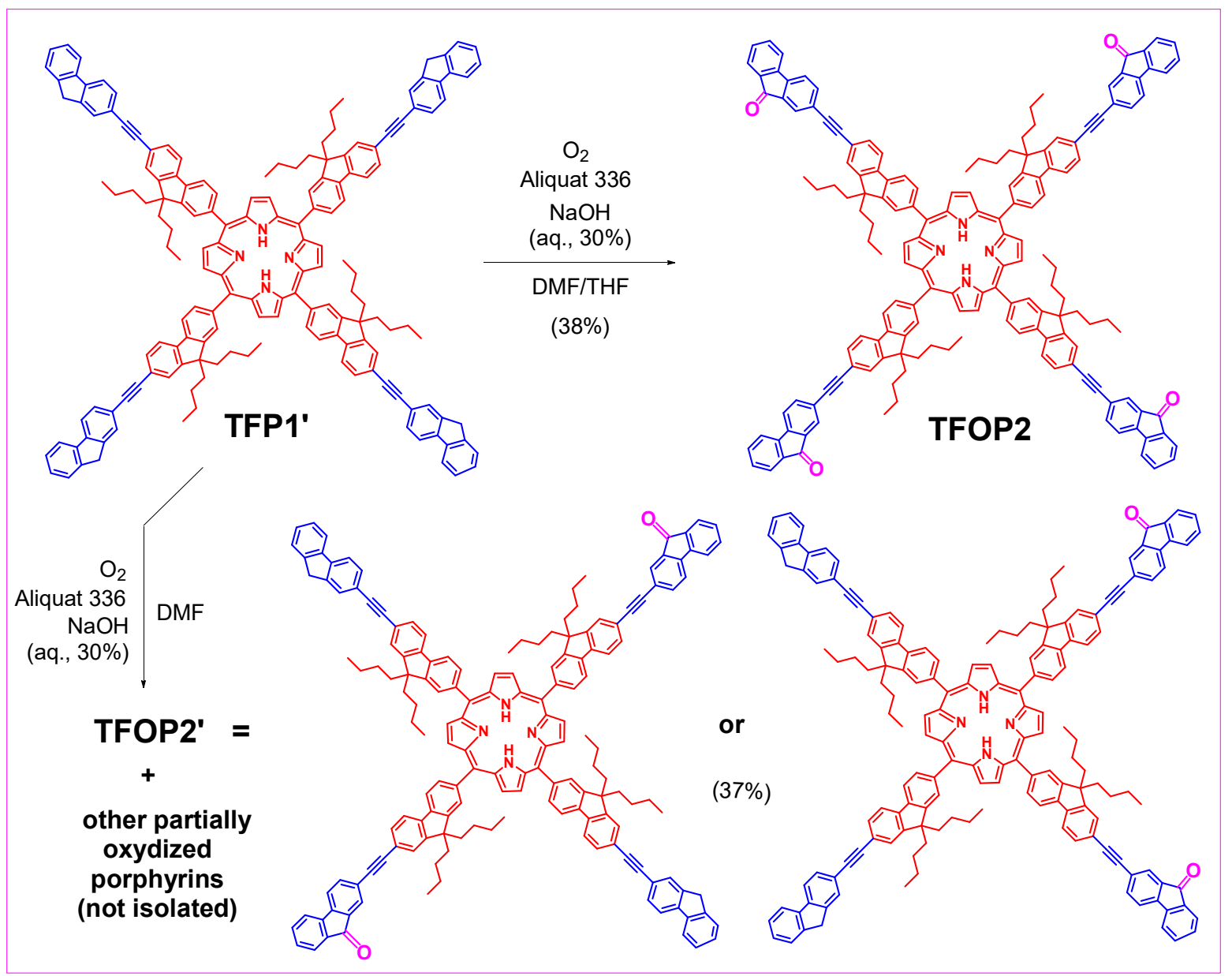

Scheme 7. Synthesis of TFOP2 and TFOP2' from precursor TFP1'.

The purity of the various porphyrin sample is established by combined mass spectrometry and elemental analysis. The new aldehyde 3 and porphyrins TFP1', TFOP2' and TFOP2 were characterized by ${ }^{1} \mathrm{H}$ NMR (see ESI). Thus, for the various porphyrin derivatives, in addition to the (i) $\beta$-pyrrolic protons of the porphyrin core which come out as a singlet around $9 \mathrm{ppm}$ and (ii) the $\mathrm{NH}$ protons of porphyrin cavity which come out as a second singlet around -2.5 ppm, some of the diagnostic features of the aldehyde $\mathbf{3}$ are retrieved, i.e. (iii) aromatic protons located as multiplets in region 8.0-7.3 ppm and (iv) alkyl protons of the various butyl chains around 2.2-0.5 ppm. In addition, for TFP1' and TFOP2', the methylene protons of nonsubstituted fluorenyl groups are also observed as diagnostic singlets at $4.1 \mathrm{ppm}$. These signals progressively disappear, upon proceeding from TFP1' to TFOP2. The ${ }^{1} \mathrm{H}$ NMR spectrum of the compound TFOP2' appears as a one-to-one superposition of the two previous spectra in the aromatic region. The cis (5,10-isomer) or trans (5,15-isomer) nature of the TFOP2' isomer isolated could not be ascertained from available data. 


\section{Photophysical properties}

In order to investigate the applied potential of these new porphyrin derivatives, we examined the absorption and emission behaviors of TFP1' and TFOP2-2' (Table 1). Their capability to photosensitize oxygen and, finally, their 2PA properties will also be subsequently measured (Table 2). During these studies, TFP, TEFP (Scheme 1), TFP-Bu and extended TFP1 ${ }^{[8 \mathrm{a}]}$ (Scheme 3) were chosen as references compound to help analyzing the influence of the fluorenone groups at periphery of these star-shaped derivatives.

\section{Absorption spectra}

The UV-visible absorption spectra of the new para-substituted porphyrins TFP1' and TFOP2-2' are typical for these free base porphyrins (Figure 1) with (i) an intense Soret-band around $430 \mathrm{~nm}$ and four Q-bands from 520-650 nm, and (ii) an extra absorption, around 310$400 \mathrm{~nm}$, which corresponds to $\pi^{*} \leftarrow \pi$ transitions in the conjugated arms..$^{[7,8]}$ This UV extra absorption, largely fluorenyl-based, is absent for TEFP, possibly because the less-conjugated meso-fluorenyl groups of TEFP absorb around $290 \mathrm{~nm}$, whereas those of the porphyrins TFP1' and TFOP2-2', conjugated with the porphyrin core through the ethynyl bridges, are strongly red-shifted $(330-350 \mathrm{~nm})$ and more intense. ${ }^{[8 \mathrm{a}]}$ Related differences can also be observed between TFP1' (or TFOP2-2') and TFP. ${ }^{[8]}$

Table 1. Photophysical properties data of the new series of fluorenone porphyrins: reference TEFP, nonoxidized TFP1' and TFOP2-2' in $\mathrm{CH}_{2} \mathrm{Cl}_{2}$ (HPLC quality) at R.T.

\begin{tabular}{|c|c|c|c|c|c|c|}
\hline & $\begin{array}{c}\lambda_{\text {dendron }} \\
/ \mathrm{nm}\end{array}$ & $\begin{array}{c}\lambda_{\text {Soret }} \\
/ \mathrm{nm}\end{array}$ & $\begin{array}{c}\lambda_{\text {Q-bands }} \\
/ \mathrm{nm}\end{array}$ & $\lambda_{\mathrm{em}} / \mathrm{nm}$ & $\begin{array}{c}\Phi_{\mathrm{F}}{ }^{\mathrm{a}} \\
/ \%\end{array}$ & $\begin{array}{c}\tau \\
/ \mathrm{ns}\end{array}$ \\
\hline TEFP & 292 & 428 & $520,558,594,652$ & 660,724 & 15 & 8.2 \\
\hline TFP1' & 340 & 431 & $521,559,596,652$ & 660,725 & $\mathbf{2 2}$ & 8.0 \\
\hline TFOP2 & 315,346 & 431 & $521,558,596,652$ & 660,725 & $\mathbf{2 1}$ & 8.0 \\
\hline TFOP2 & 310,352 & 431 & $521,560,596,652$ & 660,724 & $\mathbf{2 2}$ & 8.0 \\
\hline
\end{tabular}

\footnotetext{
${ }^{a}$ Fluorescence quantum yield determined relative to TPP in toluene.
} 
After normalizing the spectra on the Soret-band intensity, the dendron-based absorption clearly separates in two parts when going from TFP1' to TFOP2, i.e. with increasing fluorenone units (Figure 1), while the porphyrin-based transitions (Soret-band and Q-bands) remain constant. It can also be noticed that the intensity of the first dendron-based absorption gets weaker and larger with the increasing number of fluorenone units, suggesting that fluorenone sub-chromophores in TFOP2 and TFOP2' behave as weaker absorbers than do terminal fluorene units.

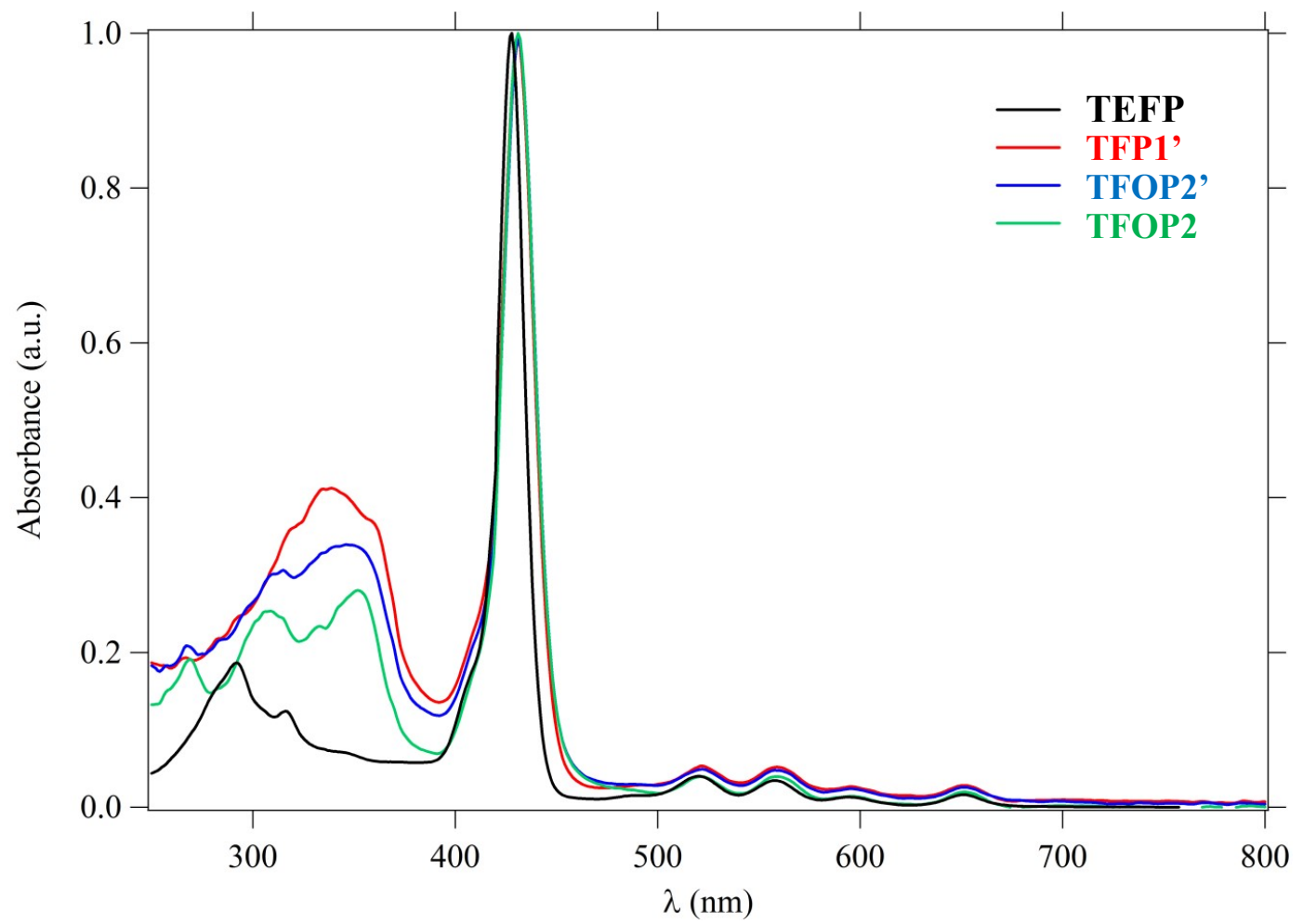

Figure 1. UV-visible spectra of porphyrins TFP1', TFOP2-2' and reference TEFP in $\mathrm{CH}_{2} \mathrm{Cl}_{2}$.

\section{Emission spectra}

Upon excitation in their Soret-band, TFP1', TFOP2-2' and the reference compound TEFP exhibit the characteristic porphyrin emission peaks $\mathrm{Q}(0,0)$ and $\mathrm{Q}(0,1) .{ }^{[7,8]}$ After normalizing the emission intensities of the various compounds on their $\mathrm{Q}(0,0)$ peaks, all four compounds exhibit similar emission spectra (Figure 2a). Then, for TFP1' and TFOP2-2', the intensity ratios between $\mathrm{Q}(0,0)$ and $\mathrm{Q}(0,1)$ remain constant, as previously observed for the porphyrincored dendrimers. ${ }^{[7,8]}$ All three compounds TFP1' and TFOP2-2' show slightly lower quantum yields $\left(\Phi_{\mathrm{F}} \sim 22 \%\right)$ than TFP-cored porphyrin dendrimers TFP1-3 ( 24\%). ${ }^{[8 \mathrm{a}]}$ However, when compared to the TPP-cored porphyrins TPP1-3 $(\sim 20 \%),{ }^{[7]}$ their luminescence 
quantum yields are slightly higher of $c a .2 \%$, in contrast to the tetra-alkynyl porphyrin TEFP (Table1).
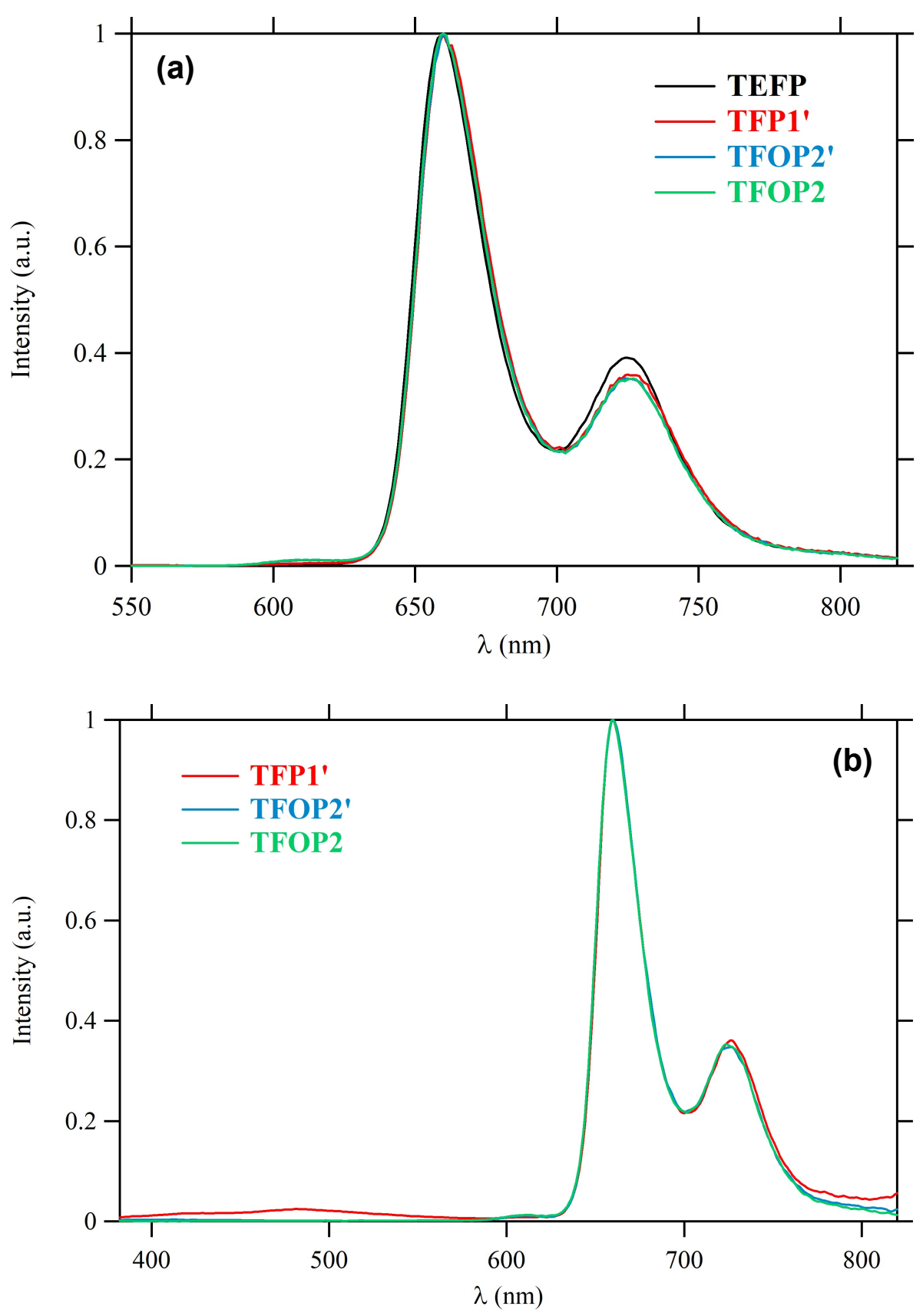

Figure 2. a) Normalized emission spectra of TEFP, TFP1' and TFOP2-2' in $\mathrm{CH}_{2} \mathrm{Cl}_{2}(500-820 \mathrm{~nm})$ after excitation in their Soret band; b) Complete normalized emission spectra of TFP1' and TFOP2-2' excited in their arm-based absorption $(380 \mathrm{~nm})$. Corresponding non-normalized spectra are provided in the ESI. 


\section{Energy Transfer from conjugated arms to porphyrin core}

The existence of an energy transfer (ET) between the peripheral arms and the central porphyrin core was also probed. Figure $2 \mathrm{~b}$ presents the emission spectra of TFP1' and TFOP2-2, upon UV excitation in the arm-based absorption $(\sim 380 \mathrm{~nm})$. The resulting emission spectra show only the red emission (at 660 and $725 \mathrm{~nm}$ ), characteristic of the porphyrin core, and no residual blue emission, characteristic of the arm, meaning that the dendron emission is completely quenched through an efficient process most likely corresponding to a through-bond ET $(\mathrm{TBET})^{[15]}$ from the peripheral fluorenone moieties to the porphyrin core via the fluorene perpendicular connectors.

\section{Oxygen Sensitization}

We next wondered about the oxygen-sensitizing capabilities of TFP1' and TFOP2-2'. The quantum yields of singlet oxygen generation were therefore determined for these compounds and compared to those of TFP1 ${ }^{[8 a]}$ (Table 2). All the new compounds exhibit values $\left(\Phi_{\Delta} \sim\right.$ $65 \%$ ) higher than that of TFP1 $\left(\Phi_{\Delta}=62 \%\right)$. Interestingly, these measurements reveal that the high fluorescence efficiency of the porphyrins (especially in comparison with model TPP) is not obtained at the expense of the singlet oxygen production.

Table 2. Photophysical properties of TFP-cored porphyrins and relevant reference compounds.

\begin{tabular}{|c|c|c|c|c|c|c|c|}
\hline Compound & $\begin{array}{c}\lambda_{\text {abs }} \text { (Soret) } \\
(\mathrm{nm})\end{array}$ & $\begin{array}{c}\boldsymbol{\varepsilon} \\
\left(\mathrm{M}^{-1} \mathrm{~cm}^{-1}\right)\end{array}$ & $\begin{array}{c}\lambda_{\mathrm{em}} \\
(\mathrm{nm})\end{array}$ & $\boldsymbol{\Phi}_{\mathrm{F}} \mathbf{a}$ & $\Phi_{\mathrm{F}} \mathbf{b}$ & $\Phi_{\Delta} \mathbf{c}$ & $\begin{array}{c}\sigma_{2} \mathbf{d}^{\mathbf{}} \\
(\mathrm{GM})\end{array}$ \\
\hline TFP & 425 & - & 659,724 & 0.24 & 0.24 & 0.60 & 90 \\
\hline TFP-Bu & 426 & - & 660,724 & 0.18 & 0.20 & 0.64 & 140 \\
\hline TFP1 & 432 & 669000 & 660,726 & 0.23 & 0.24 & 0.62 & 770 \\
\hline TFP1' & 431 & 477000 & 660,726 & 0.21 & 0.22 & 0.66 & 530 \\
\hline TFOP2 & 431 & $\mathbf{5 7 8 0 0 0}$ & $\mathbf{6 6 0 , 7 2 6}$ & $\mathbf{0 . 2 1}$ & $\mathbf{0 . 2 1}$ & $\mathbf{0 . 6 5}$ & $\mathbf{6 4 0}$ \\
\hline TFOP2 & 431 & $\mathbf{5 0 9 0 0 0}$ & $\mathbf{6 6 0 , 7 2 6}$ & $\mathbf{0 . 2 1}$ & $\mathbf{0 . 2 2}$ & $\mathbf{0 . 6 4}$ & $\mathbf{6 1 0}$ \\
\hline
\end{tabular}

${ }^{a}$ Fluorescence quantum yield in dichloromethane determined relative to TPP in toluene. ${ }^{b}$ Fluorescence quantum yield in toluene. 'Singlet oxygen formation quantum yield determined relative to tetraphenylporphyrin in dichloromethane $\left(\Phi_{\Delta}[T P P]=0.60\right)$. ${ }^{d}$ Intrinsic $2 P A$ cross-sections at $790 \mathrm{~nm}$ in dichloromethane, measured by $T P E F$ in the femtosecond regime; a fully quadratic dependence of the fluorescence intensity on the excitation power is observed and $2 P A$ responses are fully non-resonant $\left(\lambda_{\text {exc }} \geq 790 \mathrm{~nm}\right)$. 


\section{Two-Photon Absorption}

Given the important 2PA cross-sections previously evidenced TPP1 and TFP1 (Schemes 2 and 3), ${ }^{[7,8 a]}$ we finally turned our attention to the 2PA properties of TFP1' and TFOP2-2' (which exhibit quite similar two-photon absorptivities). Taking advantage of their good fluorescence, the 2PA cross-sections of these TFP-cored compounds were determined by twophoton excited fluorescence (TPEF). Measurements were performed with $10^{-4} \mathrm{M}$ solutions, using a mode-locked Ti:sapphire laser delivering femtosecond pulses, following the experimental protocol described by $\mathrm{Xu}$ and Webb. ${ }^{[16]} \mathrm{A}$ fully quadratic dependence of the fluorescence intensity on the excitation power was observed for each sample at all the wavelengths of the spectra shown in Figure 3, indicating that the cross-sections determined are only due to 2PA. A significant increase of the 2PA cross-sections compared to that of TPP (12 GM at $790 \mathrm{~nm}$ ) was observed for all the new porphyrins (Table 2).

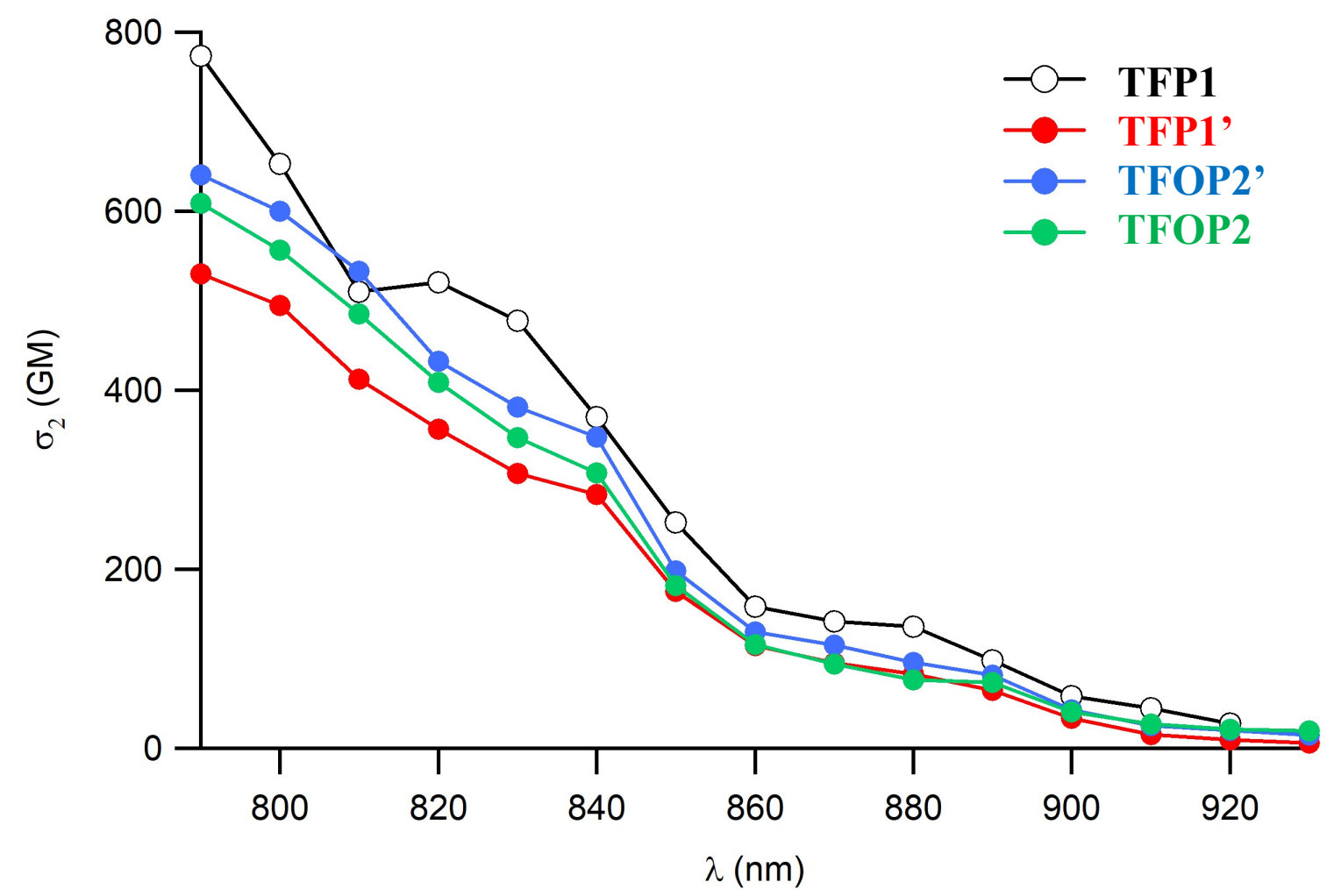

Figure 3. Two-Photon Absorption Spectra for TFP-cored compounds TFP1' and TFOP2-2' compared to TFP1 in $\mathrm{CH}_{2} \mathrm{Cl}_{2}$.

We have shown earlier that replacing the four phenyl groups at meso-positions by four fluorenyl groups leads to a clear improvement in the 2PA properties. ${ }^{[7,8]}$ When comparing 
TFP-cored porphyrins together, it appears that butyl chains on the meso-fluorenyl groups of the porphyrin in TFP-Bu (140 GM) favor TPA over bare fluorenyl arms in TFP (90 GM). Similarly, 2-fluorenone units appears more efficient for promoting 2PA than bare 2ethynylfluorenyl groups at 7-positions of meso-fluorenyl groups in TFP1' (530 GM). Thus, a TFP-Bu core decorated with such units (TFP1') is a worst two-photon absorber than TFOP2-2' (610-640 GM) or TFP1 (770 GM).

\section{Conclusions}

The synthesis and characterization of two conjugated meso-tetrafluorenylporphyrin-cored compounds peripherally functionalized with additional ethynyl-2-fluorenyl/fluorenon-2-yl units (TFOP2-2') has been reported here. These new starshaped derivatives were easily obtained by aerobic oxidation of the non-oxidized porphyrin precursor TFP1'. In terms of photophysical properties, all three new porphyrins exhibit remarkably high luminescence quantum yields $\left(\Phi_{\mathrm{F}} \sim 21-22 \%\right)$ for meso-tetraarylporphyrins and present also a potentially large brightness, thanks to the very efficient energy transfer from the peripheral arms units toward the central porphyrin core (TBET). While these high luminescence quantum yields make them potentially interesting for organic light emitting devices, these compounds behave also as efficient photosensitizers for oxygen, with quantum yields of singlet oxygen generation around $65 \%$ i.e. higher to that previously reported for TFP1 $\left(\Phi_{\Delta}=62 \%\right)$. Interestingly, their high fluorescence quantum yields (especially in comparison with the TPP model compound) are not obtained at the expense of the singlet oxygen production. Finally, their 2PA cross-sections of TFP1' and TFOP2-2', when compared to that of TFP (90 GM), are much larger ( $\sim 600 \mathrm{GM})$ pointing to the beneficial impact of increasing the size of the $\pi$-manifold in the peripheral arms. Actually, TFOP2 and TFOP2' exhibit quite similar two-photon absorptivities (640-610 GM), which are significantly higher than for the non-oxidized compound TFP1' (530 GM), in line with a beneficial role of 2-fluorene for 2-fluorenone replacement on nonlinear absorption properties. Thus, combined to their remarkable fluorescence quantum yields and oxygen-photosensitizing properties, their rather large 2PA cross-sections make them potentially interesting for applications in theranostics. After proper functionalization, this type of structure should, likewise to related systems recently developed for such uses, ${ }^{[10 b, 11]}$ give rise to original porphyrin-based molecular assemblies combining two-photon PDT and two-photon fluorescence imaging. In connection with previous results, ${ }^{[11 b]}$ the replacement of peripheral 
9,9-dibutyl-9H-fluoren-2-yl units by units by $9 H$-fluoren-9-one-2-yl units in the corresponding water-soluble star-shaped analogues should therefore not drastically affect their 2PA cross-section, nor their relevant linear optical properties. However, other important properties such as their solubility, self-aggregation or bio-distribution might be more profoundly modified. As such, oxidation of the peripheral 2-fluorenyl units should be envisioned as a potential mean to improve the overall efficiency of two-photon photosensitizers related to TFP1' or TFP1.

\section{Experimental Section}

\section{General}

Unless otherwise stated, all solvents used in reactions were distilled using common purification protocols, ${ }^{[17]}$ except DMF and ${ }^{i} \operatorname{Pr}_{2} \mathrm{NH}$ which were dried on molecular sieves (3 $\AA$ ). Compounds were purified by chromatography on silica gel using different mixtures of eluents as specified. ${ }^{1} \mathrm{H}$ and ${ }^{13} \mathrm{C}$ NMR spectra were recorded on BRUKER Ascend 400 and 500 at $298 \mathrm{~K}$. The chemical shifts are referenced to internal tetramethylsilane. High-resolution mass spectra were recorded on different spectrometers: a Bruker MicrOTOF-Q II, a Thermo Fisher Scientific Q-Exactive in ESI positive mode and a Bruker Ultraflex III MALDI Spectrometer at CRMPO (centre regional de mesures physiques de l'Ouest) in Rennes. Reagents were purchased from commercial suppliers and used as received. Compounds 7bromo-9,9-dibutyl-fluorene-2-carboxaldehyde (1) ${ }^{[8 \mathrm{a}]}$ and 2-ethynyl-fluorene $(\mathbf{2}){ }^{[7 \mathrm{~b}]}$ were synthesized as described earlier, using an adapted approach for 2 (ESI).

\section{Synthesis of organic precursors}

Difluorenyl aldehyde 3. In a Schlenk tube, a mixture of 7-bromo-9,9-dibutylfluorene-2-carboxaldehyde (1) (492 mg, $1.28 \mathrm{mmol}, 1$ equiv), 2-ethynyl-fluorene (2) (365 mg, $1.92 \mathrm{mmol}, 1.5$ equiv), $\mathrm{Pd}\left(\mathrm{PPh}_{3}\right)_{2} \mathrm{Cl}_{2}$ (5.4 mg, $0.008 \mathrm{mmol}, 0.6 \%$ equiv.) and $\mathrm{CuI}$ (excess) were dissolved in DMF $(5 \mathrm{~mL})$ and then ${ }^{i} \mathrm{Pr}_{2} \mathrm{NH}(5 \mathrm{~mL})$ was added under argon. The reaction 
medium was degassed by freeze-pump-thaw twice and heated for $48 \mathrm{~h}$ at $95{ }^{\circ} \mathrm{C}$. After evaporation of the volatiles, residue was further purified by silica chromatography using heptane as eluent; the desired aldehyde 3 (398 mg, 63\% yield) was obtained as a yellow powder. ${ }^{1} \mathrm{H}$ NMR (400 MHz, $\mathrm{CDCl}_{3}$ ): $\delta=10.07$ (s, 1H, $\mathrm{H}_{\mathrm{CHO}}$ ), 7.89-7.76 (m, 7H, $\mathrm{H}_{\text {fluorenyl }}$ ),

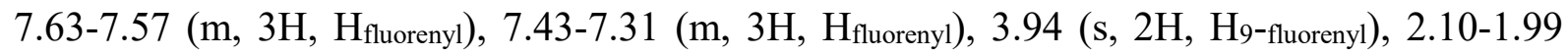
$\left(\mathrm{m}, 4 \mathrm{H}, \mathrm{H}_{\mathrm{a}}\right), 1.16-1.04\left(\mathrm{~m}, 4 \mathrm{H}, \mathrm{H}_{\mathrm{c}}\right), 0.70-0.44\left(\mathrm{~m}, 10 \mathrm{H}, \mathrm{H}_{\mathrm{b}}, \mathrm{H}_{\mathrm{d}}\right) .{ }^{13} \mathrm{C} \mathrm{NMR}\left(100 \mathrm{MHz}, \mathrm{CDCl}_{3}\right.$, ppm): $\delta=186.5,161.0,157.6,156.2,155.2,150.9,150.6,149.0,143.1,139.5,139.1,138.3$, 137.8, 133.6, 131.2, 130.7, 128.3, 105.1, 99.5, 99.4, 41.5, 40.4, 33.2, 23.9, 11.1. HRMS-ESI for $\mathrm{C}_{37} \mathrm{H}_{35} \mathrm{O}: \mathrm{m} / \mathrm{z}=495.2680[\mathrm{M}+\mathrm{H}]^{+}$(calcd: 495.26824).

Porphyrin TFP1'. In a two-neck flask, a mixture of previously prepared difluorenyl aldehyde 3 (564 mg, $1.14 \mathrm{mmol}, 1$ equiv.) and pyrrole (0.08 mL, $1.14 \mathrm{mmol}, 1$ equiv.) were dissolved in distilled chloroform $(250 \mathrm{~mL})$ under argon. After degassing the mixture with argon bubbling for $30 \mathrm{~min}, \mathrm{BF}_{3} \bullet \mathrm{OEt}_{2}(0.04 \mathrm{~mL}, 0.29 \mathrm{mmol}, 0.25$ equiv. $)$ was injected and the reaction was stirred in dark for $3 \mathrm{~h}$ under argon at room temperature. Then oxidant $p$-chloranil ( $210 \mathrm{mg}, 0.86 \mathrm{mmol}, 0.75$ equiv.) was added, and the reaction was heated at $45^{\circ} \mathrm{C}$ for another $1 \mathrm{~h}$ without any protection. After cooling the reaction to room temperature, $\mathrm{NEt}_{3}(2 \mathrm{~mL})$ was injected, and then keep stirring for several minutes. After evaporation of the volatiles, purification was done by silica gel chromatography using THF/heptane (1:4) mixture as eluents, the porphyrin TFP1' was collected as violet powder (110 mg, 18\% yield). MP: 216$218^{\circ} \mathrm{C}$ (dec). Rf: 0.72 (THF/Heptane [1:1]). ${ }^{1} \mathrm{H}$ NMR (300 MHz, THF- $\left.d_{8}\right): \delta=8.94(\mathrm{~s}, 8 \mathrm{H}$,

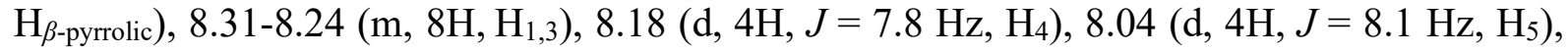
7.87-7.83 (m, 8H, H10,12), 7.76 (d, 4H, J=8.4 Hz, H6,8), 7.67 (d, 4H, J=7.8 Hz, H13), 7.617.55 (m, 8H, $\left.\mathrm{H}_{14,17}\right), 7.39-7.27$ (m, 8H, $\left.\mathrm{H}_{15,16}\right), 3.95$ (s, 8H, $\left.\mathrm{H}_{18}\right), 2.25$ (s, 16H, $\mathrm{H}_{\mathrm{a}}$ ), 1.28-1.19 $\left(\mathrm{m}, 16 \mathrm{H}, \mathrm{H}_{\mathrm{c}}\right), 1.10-0.94\left(\mathrm{~m}, 16 \mathrm{H}, \mathrm{H}_{\mathrm{b}}\right), 0.83-0.77\left(\mathrm{~m}, 24 \mathrm{H}, \mathrm{H}_{\mathrm{d}}\right),-2.50(\mathrm{~s}, 2 \mathrm{H}, \mathrm{NH}) .{ }^{13} \mathrm{C} \mathrm{NMR}$ (100 MHz, $\left.\mathrm{CDCl}_{3}, \mathrm{ppm}\right): \delta=151.2,149.4,143.7,143.4,141.9,141.5,141.3,141.0,140.4$, $133.5,130.7,130.2,129.3,128.6,127.9,127.0,126.7,125.9,124.8,122.5,121.6,120.6$, $120.1,119.9,119.7,118.2,90.4,90.2,55.2,40.1,36.2,29.6,26.4,13.4$. HRMS-ESI for $\mathrm{C}_{164} \mathrm{H}_{143} \mathrm{~N}_{4}: \mathrm{m} / \mathrm{z}=2168.1231[\mathrm{M}+\mathrm{H}]^{+}$(calcd: 2168.13073). Anal. Calcd. (\%) for $\mathrm{C}_{164} \mathrm{H}_{142} \mathrm{~N}_{4} \cdot 3 \mathrm{THF}$ : C 88.62; H 7.01; N 2.35. Found: C 88.71; H 7.15; N, 2.32. 
Partially Oxidized porphyrin TFOP2'. In a two-neck flask, non-oxidized TFP1' (50 $\mathrm{mg}, 0.02$ mmol, 1 equiv.) is dissolved in $1 \mathrm{~mL}$ of DMF. Aqueous $\mathrm{NaOH}(30 \%, 4.6 \mathrm{~mL})$ is carefully added, followed by addition of Aliquat 336 (tricaprylmethylammonium chloride). The mixture is stirred for $59 \mathrm{~h}$. Reaction progress is monitored by TLC, spotting directly from the organic layer. Then, the dark violet solution is separated and concentrated. The crude is chromatographed on silica gel column with THF/heptane (1:4) as eluent, the title porphyrin is obtained as dark violet powder $\left(19 \mathrm{mg}, 37 \%\right.$ yield). MP: $238-240{ }^{\circ} \mathrm{C}$ (dec). Rf: 0.56 (THF/Heptane [1:1]). ${ }^{1} \mathrm{H}$ NMR (300 MHz, THF- $\left.d_{8}\right): \delta=8.93$ (s, 8H, $\mathrm{H}_{\beta \text {-pyrrolic }}$ ), 8.34-8.18 (m,

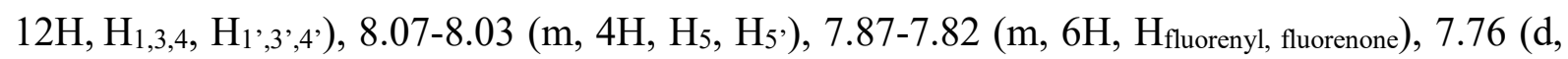

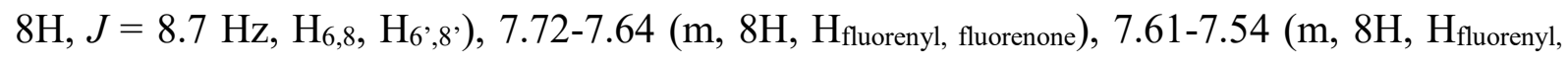
fluorenone), 7.39-7.27 (m, 8H, $\mathrm{H}_{15,16}, \mathrm{H}_{15}{ }^{\prime}, 16$ '), 3.96 (s, 8H, $\left.\mathrm{H}_{18}\right), 2.25$ (s, 16H, $\left.\mathrm{H}_{\mathrm{a}}, \mathrm{H}_{\mathrm{a}}{ }^{\prime}\right), 1.25-1.16$ $\left(\mathrm{m}, 16 \mathrm{H}, \mathrm{H}_{\mathrm{c}}, \mathrm{H}_{\mathrm{c}}{ }^{\prime}\right), 1.10-0.93\left(\mathrm{~m}, 16 \mathrm{H}, \mathrm{H}_{\mathrm{b}}, \mathrm{H}_{\mathrm{b}}{ }^{\prime}\right), 0.87-0.77$ (m, 24H, $\left.\mathrm{H}_{\mathrm{d}}, \mathrm{H}_{\mathrm{d}}{ }^{\prime}\right),-2.50$ (s, 2H, NH). UV-vis $\left(\lambda \max , \mathrm{CH}_{2} \mathrm{Cl}_{2}, \mathrm{~nm}\right): 351,431,521,560,596,652$. HRMS-ESI for $\mathrm{C}_{164} \mathrm{H}_{139} \mathrm{~N}_{4} \mathrm{O}_{2}$ $: \mathrm{m} / \mathrm{z}=2196.0847[\mathrm{M}+\mathrm{H}]^{+}$(calcd: 2196.08926). Anal. Calcd. (\%) for $\mathrm{C}_{164} \mathrm{H}_{138} \mathrm{~N}_{4} \mathrm{O}_{2} \cdot 3 \mathrm{THF}: \mathrm{C}$ 87.60; H 6.77; N 2.32. Found: C 87.98; H 6.52; N, 2.25.

Fully-Oxidized Porphyrin TFOP2. In a two-neck flask, non-oxidized TFP1' (36 mg, $0.02 \mathrm{mmol}, 1$ equiv. $)$ is dissolved in DMF $(1 \mathrm{~mL})$ and THF $(1 \mathrm{~mL})$. Aqueous $\mathrm{NaOH}(30 \%$, $4.6 \mathrm{ml}$ ) is carefully added, followed by addition of Aliquat 336 (tricaprylmethylammonium chloride). The mixture is stirred for $72 \mathrm{~h}$. Reaction progress is monitored by TLC, spotting directly from the organic layer. Then, the dark violet solution is separated and concentrated. The crude is chromatographed on silica gel column with THF/heptane (1:1) as eluent, TFOP2 is obtained as dark violet powder $\left(14 \mathrm{mg}, 38 \%\right.$ yield). MP: $237-239{ }^{\circ} \mathrm{C}$ (dec). Rf: 0.40 (THF/Heptane [1:1]). ${ }^{1} \mathrm{H}$ NMR (300 MHz, THF- $\left.d_{8}\right): \delta=8.93$ (s, 8H, $\mathrm{H}_{\beta \text {-pyrrolic }}$ ), 8.32-8.25 (m, $\left.8 \mathrm{H}, \mathrm{H}_{1,3}\right), 8.19\left(\mathrm{~d}, 4 \mathrm{H}, J=7.8 \mathrm{~Hz}, \mathrm{H}_{4}\right), 8.05\left(\mathrm{~d}, 4 \mathrm{H}, J=7.8 \mathrm{~Hz}, \mathrm{H}_{5}\right), 7.82-7.64(\mathrm{~m}, 28 \mathrm{H}$,

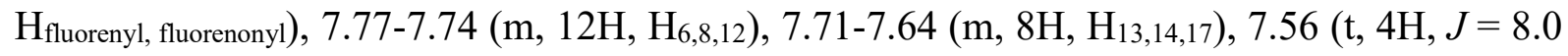
$\left.\mathrm{Hz}, \mathrm{H}_{15}\right), 7.36$ (t, 4H, J=7.4 Hz, H16), 2.25 (t, $\left.J=7.8 \mathrm{~Hz}, 16 \mathrm{H}, \mathrm{H}_{\mathrm{a}}\right), 1.26-1.16\left(\mathrm{~m}, 16 \mathrm{H}, \mathrm{H}_{\mathrm{c}}\right.$ ), 1.11-0.93 (m, 16H, Hb), 0.82-0.77 (m, 24H, H $),-2.50(\mathrm{~s}, 2 \mathrm{H}, \mathrm{NH}) .{ }^{13} \mathrm{C}$ NMR $(100 \mathrm{MHz}$, $\left.\mathrm{CDCl}_{3}, \mathrm{ppm}\right): \delta=193.5,153.2,151.4,145.8,145.6,143.6,143.5,142.1,139.1,136.6,136.2$, $135.3,132.8,131.2,128.2,128.0,126.2,125.7,123.6,122.6,122.5,122.4,122.0,120.2,93.8$, 90.6, 57.2, 31.5, 28.3, 24.9, 15.3. HRMS-ESI for $\mathrm{C}_{164} \mathrm{H}_{135} \mathrm{~N}_{4} \mathrm{O}_{4}: \mathrm{m} / \mathrm{z}=2224.0442[\mathrm{M}+\mathrm{H}]^{+}$ 
(calcd: 2224.04778). Anal. Calcd. (\%) for $\mathrm{C}_{164} \mathrm{H}_{134} \mathrm{~N}_{4} \mathrm{O}_{4} 3$ THF: C 86.59; H 6.52; N 2.30. Found: C 86.56; H 6.57; N, 2.07.

\section{Spectroscopic Measurements}

All photophysical measurements have been performed with freshly-prepared air-equilibrated solutions at room temperature (298 K). UV-Vis absorption spectra were recorded on a Jasco V-570 spectrophotometer. Steady-state fluorescence measurements were performed on dilute solutions (ca. $10^{-6} \mathrm{M}$, optical density $<0.1$ ) contained in standard $1 \mathrm{~cm}$ quartz cuvettes using an Edinburgh Instrument (FLS920) spectrometer in photon-counting mode. Fully corrected emission spectra were obtained, for each compound, after excitation at the wavelength of the absorption maximum, with $\mathrm{A} \lambda_{\mathrm{ex}}<0.1$ to minimize internal absorption.

\section{Measurements of singlet oxygen quantum yield $\left(\Phi_{\Delta}\right)$}

Measurements were performed on a Fluorolog-3 (Horiba Jobin Yvon), using a $450 \mathrm{~W}$ Xenon lamp. The emission at $1272 \mathrm{~nm}$ was detected using a liquid nitrogen-cooled Ge-detector model (EO-817L, North Coast Scientific Co). Singlet oxygen quantum yields $\Phi_{\Delta}$ were determined in dichloromethane solutions, using tetraphenylporphyrin (TPP) in dichloromethane as reference solution $\left(\Phi_{\Delta}[\mathrm{TPP}]=0.60\right)$ and were estimated from ${ }^{1} \mathrm{O}_{2}$ luminescence at $1272 \mathrm{~nm}$.

\section{Two-Photon Absorption Experiments}

To span the 790-920 nm range, a Nd:YLF-pumped Ti:sapphire oscillator (Chameleon Ultra, Coherent) was used generating $140 \mathrm{fs}$ pulses at a $80 \mathrm{MHz}$ rate. The excitation power is controlled using neutral density filters of varying optical density mounted in a computercontrolled filter wheel. After five-fold expansion through two achromatic doublets, the laser beam is focused by a microscope objective (10×, NA 0.25 , Olympus, Japan) into a standard 1 $\mathrm{cm}$ absorption cuvette containing the sample. The applied average laser power arriving at the sample is typically between 0.5 and $40 \mathrm{~mW}$, leading to a time-averaged light flux in the focal volume on the order of $0.1-10 \mathrm{~mW} / \mathrm{mm}^{2}$. The fluorescence from the sample is collected in epifluorescence mode, through the microscope objective, and reflected by a dichroic mirror 
(Chroma Technology Corporation, USA; "blue" filter set: 675dcxru; "red" filter set: 780dxcrr). This makes it possible to avoid the inner filter effects related to the high dye concentrations used $\left(10^{-4} \mathrm{M}\right)$ by focusing the laser near the cuvette window. Residual excitation light is removed using a barrier filter (Chroma Technology; "blue": e650-2p, "red": e750sp-2p). The fluorescence is coupled into a $600 \mu \mathrm{m}$ multimode fiber by an achromatic doublet. The fiber is connected to a compact CCD-based spectrometer (BTC112E, B\&WTek, USA), which measures the two-photon excited emission spectrum. The emission spectra are corrected for the wavelength-dependence of the detection efficiency using correction factors established through the measurement of reference compounds having known fluorescence emission spectra. Briefly, the set-up allows for the recording of corrected fluorescence emission spectra under multiphoton excitation at variable excitation power and wavelength. TPA cross sections $\left(\sigma_{2}\right)$ were determined from the two-photon excited fluorescence (TPEF) cross sections $\left(\sigma_{2} . \Phi_{\mathrm{F}}\right)$ and the fluorescence emission quantum yield $\left(\Phi_{\mathrm{F}}\right)$. TPEF cross sections of $10^{-4} \mathrm{M}$ dichloromethane solutions were measured relative to fluorescein in $0.01 \mathrm{M}$ aqueous $\mathrm{NaOH}$ using the well-established method described by $\mathrm{Xu}$ and $\mathrm{Webb}^{[16]}$ and the appropriate solvent-related refractive index corrections. ${ }^{[18]}$ The quadratic dependence of the fluorescence intensity on the excitation power was checked for each sample and all wavelengths.

Supporting Informations. Synthetic details, ${ }^{1} \mathrm{H}$ NMR and mass spectra of all new compounds. This material is available free of charge via the Internet at http://pubs.acs.org.

\section{Conflict of Interest}

\section{Acknowledgements}

The authors acknowledge CNRS for their financial support and China Scholarship Council (CSC) for $\mathrm{PhD}$ funding (XZ and $\mathrm{ZS}$ ). This project was supported by the departmental committees CD35, CD28 and CD29 of the "Ligue contre le Cancer du Grand-Ouest". We also thank Guillaume Clermont (ISM) for his help in the two-photon and singlet oxygen measurements. 


\section{References}

1 W.-Y. Wong and C.-L. Ho, Coord. Chem. Rev., 2009, 253, 1709-1753.

2 Zang, X. H.; Xie, Z. Y.; Wu, F. P.; Zhou, L. L.; Wong, O. Y.; Lee, C. S.; Kwong, H. L.; Lee, S. T.; Wu, S. K. Chem. Phys. Lett. 2003, 382, 561-566.

3 a) Baldo, M. A.; O'Brien, D. F.; You, Y.; Shoustikov, A.; Sibley, S.; Thompson, M. E.; Forrest, S. R. Nature 1998, 395, 151-154; b) Virgili, T.; Lidzey, D. G.; Bradley, D. D. C. Synth. Metals 2000, 111-112, 203-206.

4 a) Z. Fei, B. Li, Z. Bo, R. Lu, Org. Lett. 2004, 6, 4703 - 4706; b) B. Li, J. Li, Y. Fu, Z. Bo, J. Am. Chem. Soc., 2004, 126, 3430-3436; c) B. Li, X. Xu, M. Sun, Y. Fu, G. Yu, Y. Liu, Z. Bo, Macromolecules, 2006, 39, 456.

5 a) Paul-Roth, C. O.; Williams, J. A. G.; Letessier, J.; Simonneaux, G. Tetrahedron Letters 2007, 48, 4317-4322; b) Drouet, S.; Paul-Roth, C. O.; Fattori, V.; Cocchi, M.; Williams, J. A. G. New J. Chem. 2011, 35, 438-444; c) C. O. Paul-Roth, S. Drouet, A. Merhi, J. A. G. Williams, L. F. Gildea, C. Pearson, M.C. Petty, Tetrahedron 2013, 69, 9625-9632.

6 a) Paul-Roth, C. O.; Simonneaux, G. Tetrahedron Letters 2006, 47, 3275-3278; b) PaulRoth, C. O.; Simonneaux, G. C.R. Acad. Sci., Ser. IIb: Chim. 2006, 9, 1277-1286.

7 a) Yao, D.; Hugues, V.; Blanchard-Desce, M.; Mongin, O.; Paul-Roth, C. O.; Paul, F. New J. Chem. 2015, 39, 7730-7733. (b) D. Yao, X. Zhang, O. Mongin, F. Paul, C. O. Paul-Roth, Chem. Eur. J., 2016, 22, 5583-5592.

8 a) Yao, D.; Hugues, V.; Blanchard-Desce, M.; Mongin, O.; Paul-Roth, C. O.; Paul, F. Chem. Eur. J., 2017, 23, 2635- 2647; b) X. Zhang, S. Ben Hassine, N. Richy, O. Mongin, M. Blanchard-Desce, F. Paul, C. O. Paul-Roth, New J. Chem. 2020, 44, 41444157.

9 a) L. B. Josefsen, R. W. Boyle, Theranostics 2012, 2, 916-966. b) P.-C. Lo, M. S. Rodriguez-Morgade, R. K. Pandey, D. K. P. Ng, T. Torres and F. Dumoulin, Chem. Soc. Rev., 2020, 49, 1041-1056.

10 See for instance: a) Z. Sun, L.-P. Zhang, F. Wu, Y. Zhao, Adv. Funct. Mater., 2017, 27, 1704079; b) F. Bolze, S. Jenni, A. Sour, V. Heitz, Chem. Commun., 2017, 53, 12857- 
12877 and refs therein; c) M. Khurana, H. A. Collins, A. Karotki, H. L. Anderson, D. T. Cramb, B. C. Wilson, Photochem. Photobiol., 2007, 83, 1441-1448.

11 a) L. Shi, C. Nguyen, M. Daurat, A. C. Dhieb, W. Smirani, M. Blanchard-Desce, M. Gary-Bobo, O. Mongin, C. Paul-Roth, F. Paul, Chem. Commun. 2019, 55, 1223112234; b) J. Schmitt, S. Jenni, A. Sour, V. Heitz, F. Bolze, A. Pallier, C. S. Bonnet, É. Tóth and B. Ventura, Bioconjugate Chem., 2018, 29, 3726-3738; c) J. R. Starkey, E. M. Pascucci, M. A. Drobizhev, A. Elliott and A. K. Rebane, Biochim. Biophys. Acta, 2013, 1830, 4594-4603; d) H. A. Collins, M. Khurana, E. H. Moriyama, A. Mariampillai, E. Dahlstedt, M. Balaz, M. K. Kuimova, M. Drobizhev, V. X. D. Yang, D. Phillips, A. Rebane, B. C. Wilson, H. L. Anderson, Nat. Photonics, 2008, 2, 420-424.

12 See for instance: a) O. Mongin, M. Sankar, M. Charlot, Y. Mir and M. BlanchardDesce, Tetrahedron Lett., 2013, 54, 6474-6478; b) M. A. Oar, W. R. Dichtel, J. M. Serin, J. M. J. Frechet, J. E. Roger, J.E. Slagla, P. A. Fleiz, L. S. Tan, T. Y. Ohulchanskyy, P. N. Prasad, Chem. Mater., 2006, 18, 3682-3692. ; c) M. A. Oar, J. M. Serin, W. R. Dichtel, J. M. J. Frechet, T. Y. Ohulchanskyy, P. N. Prasad, Chem. Mater., 2005, 17, 2267-2275.

13 a) J. S. Lindsey, H. C. Hsu, I. C. Schreiman, Tetrahedron Lett., 1986, 27, 4969-5012; b) J. S. Lindsey, I. C. Schreiman, H. C. Hsu, P. C. Kearney, A. M. Marguerettaz, J. Org. Chem., 1987, 52, 827-845.

14 K. Sonogashira, Y. Tohda, N. Hagihara, Tetrahedron Lett., 1975, 50, 4467.

15 D. Cao, L. Zhu, Z. Liu, W. Lin J. Photochem. Photobiol. C, 2020, 44, 100371.

16 Xu, C.; Webb, W. W. J. Opt. Soc. Am. B 1996, 13, 481-491

17 Perrin, D. D.; Armarego, W. L. F. Purification of Laboratory Chemicals, 3rd edn., Pergamon Press, Oxford, 1988.

18 Werts, M. H. V.; Nerambourg, N.; Pélégry, D.; Le Grand, Y.; Blanchard-Desce, M. Photochem. Photobiol. Sci. 2005, 4, 531-538. 